\title{
A case report of acute rheumatic fever and a brief review of the literature
}

Shaheen Sombans ${ }^{1}$, Ruhi Sonaye ${ }^{2}$, Kamleshun Ramphul ${ }^{3}$

\author{
${ }^{1}$ Department of Internal Medicine, Medical College, Bharati Vidyapeeth Deemed \\ University, Pune, India \\ ${ }^{2}$ Department of Internal Medicine, Medical College, Bharati Vidyapeeth University, \\ Hospital, Sangli, India \\ ${ }^{3}$ Department of Pediatrics, Shanghai Xin Hua Hospital Affiliated to Shanghai Jiao \\ Tong University, School of Medicine, Shanghai, China
}

Submitted: 6 April 2018

Accepted: 22 April 2018

Arch Med Sci Atheroscler Dis 2018; 3: e80-e82

DOI: https://doi.org/10.5114/amsad.2018.76825

Copyright @ 2018 Termedia \& Banach

Acute rheumatic fever (ARF) is an inflammatory condition affecting different organs and organ systems. It can affect the heart, joints, central nervous system and subcutaneous tissues [1, 2]. It is believed to be a delayed sequela from an infection secondary to group A streptococcus (GAS). The first symptoms of the disease classically present two to three weeks after an infection with GAS. About $80 \%$ of affected patients present with carditis that can eventually lead to regurgitation [3]. A large proportion of patients also report painful joints. Chorea, erythema marginatum and subcutaneous nodules are other less commonly reported symptoms.

We present a case report of a patient with acute rheumatic fever followed by a brief discussion on the epidemiology, pathogenesis, diagnosis and treatment options for this condition.

A 32-year-old woman presented to the Emergency Department with an initial complaint of pain and swelling in her lower extremities for $54 \mathrm{~h}$, more severe in her left knee over the last $48 \mathrm{~h}$. She denied any history of recent or past trauma to that region. She further added that she had previously experienced similar pain in her elbows and ankles. She did not seek any medical help at the time and her symptoms subsided with an over-the-counter nonsteroidal anti-inflammatory drug (NSAID).

On physical examination, the patient was afebrile with normal blood pressure, pulse rate and respiratory rate. The right lower extremity was normal with no edema, deformity or restricted range of motion. On the left side, she showed signs of tenderness in both the medial and lateral aspects of her left knee. She did not have any hepatosplenomegaly, and no other systemic abnormalities were found. She was prescribed painkillers and sent home.

The patient presented again 10 days later with more severe pain in different joints, mostly her ankles, wrists and knees. She reported that the symptoms had not improved since her last visit and she was unable to come earlier because of her job. The physician in charge found blanching erythematous plaques over her body, most noticeably over the trunk and back. Subcutaneous nodules were also found on both arms. No murmurs were heard on auscultation and her neurologic examination was without any abnormalities. She was immediately admitted for further examination with a suspected diagnosis of acute rheumatic fever. A throat cul-

\author{
Corresponding author: \\ Dr. Shaheen Sombans \\ Department \\ of Internal Medicine \\ Bharati Vidyapeeth \\ Deemed University \\ Medical College \\ 78/A, Jalavayu Vihar \\ Kphb, Kukatpally \\ 500072 Hyderabad \\ Pune, India \\ Phone: +91 8297954727 \\ E-mail: shaheensombans- \\ rodomontade@gmail.com
}


ture was found negative for group A streptococcus but she had elevated titers of antistreptolysin 0 (ASO) and antideoxyribonuclease B (ADN-B). She also tested negative for human immunodeficiency virus (HIV), Chlamydia trachomatis, Neisseria gonorrhoeae and syphilis. She showed signs of acute infection with an elevated white blood cell count of $14.6 / \mathrm{mm}^{3}$ with an elevated erythrocyte sedimentation rate (ESR) of $62 \mathrm{~mm} / \mathrm{h}$. Her hemoglobin was normal at $13.2 \mathrm{~g} / \mathrm{dl}$. She was scheduled for a cardiac electrocardiogram and echocardiogram that revealed no abnormalities. The patient was started on aspirin and her symptoms gradually subsided over the next $48 \mathrm{~h}$. She was discharged on high dose aspirin and oral penicillin and scheduled for regular cardiac follow-ups. At each visit, her white blood cell count, ESR, bleeding profiles, ASO and ADN-B levels were monitored closely and a cardiac echocardiogram was performed.

Acute rheumatic fever has a worldwide incidence of 19 cases per 100 000, and in the United States the prevalence ranges from 2 to 14 cases per $100000[4,5]$. The pathogenesis of ARF is still not fully understood as previous studies have been limited by the lack of a suitable animal model [6]. It is strongly believed that streptococcal pharyngeal infection from certain subtypes is the main factor causing this condition, and five chromosome patterns, $A$ to $E$, have been identified on the emm genes that code for the $M$ and the $M$-like surface proteins responsible for the virulence factor. Acute rheumatic fever is only associated with streptococcal pharyngitis. Many outbreaks of impetigo causing glomerulonephritis have also been documented, but they almost never caused ARF [7]. Activation of the innate immune system following group A streptococcus pharyngeal infection leads to bacterial antigens presenting to the patient's T cells. Certain studies have also proved that susceptibility to ARF is most likely polygenic [8]. Initiation of tissue injury is related to molecular mimicry. Antibodies directed against bacterial antigens can cross-react with host antigens. $\alpha$-Helical protein structures found in $\mathrm{M}$ protein and $\mathrm{N}$-acetyl- $\beta$-D-glucosamine that form a part of the carbohydrate antigen of GAS also share epitopes with myosin [9-12]. Molecular mimicry is also believed to be the cause of chorea as the antibodies target both NABG and lysoganglioside [13].

Diagnosis of ARF is currently based on the Jones criteria. The presence of either two major criteria or one major criterion and two minor along with positive evidence of recent group A streptococcal infection is required to establish the diagnosis of acute rheumatic fever [14]. Recent updates in diagnostic criteria also encouraged the use of echocardiography to confirm the diagnosis of carditis. Major diagnostic criteria include carditis, arthritis, chorea, subcutaneous nodules and erythema marginatum. About $50-65 \%$ of patients with ARF have clinically detectable carditis that leads to valvular regurgitation. Carditis usually develops over weeks to months. The most commonly affected valve is usually the mitral valve, followed by the aortic valve [15]. Congestive cardiac failures can occur if untreated and severe carditis develops [3]. Arthritis presents as migratory and asymmetrical. It involves mostly the large joints, causing edema, pain, rubor and limited movement. Up to $15 \%$ of ARF patients present with chorea, and it is more common in females and adolescents [16]. The onset of chorea usually occurs after a long latent period when most of the inflammatory symptoms are resolved. Patients present with involuntary jerky movements such as clumsiness and hemichorea and also have deterioration in performing daily activities such as feeding or have an unsteady gait. Erythema marginatum is a rare presentation that occurs in less than $5 \%$ of cases, appearing as an annular erythema on the upper and lower extremities and torso. The edges are raised and the rash is not painful or itchy $[17,18]$. Subcutaneous nodules are another rare finding that forms part of the major criteria. They present as small painless mobile nodules on extensor surfaces of wrists, elbows, knees and ankles. They usually appear during the first few weeks and can even be found in the spine [16]. Minor criteria of diagnosis include symptoms such as fever, arthralgia, first degree heart block, elevated acute phase reactants and presence of prior group A streptococcus infection. Arthralgia is not used as a minor criterion if polyarthritis is already present. It is often missed by physicians since the patients start self-medicating themselves with anti-inflammatory drugs such as NSAIDs, as was seen in this case report. First degree heart block can be used as a minor criterion if there is no evidence of carditis. Nonspecific symptoms such as fever also form part of the minor criteria. Laboratory findings such as an elevated ESR can also be used as a minor criterion along with evidence showing a recent group A streptococcal infection. A fourfold rise or fall in titers is diagnostic for a recent streptococcal infection. Commonly tested antibodies include deoxyribonucleic (anti-DNase B) antibodies and anti-streptolysin O titer (ASOT).

There are multiple conditions that may mimic symptoms resembling ARF that need to be ruled out. These include congenital heart disease, viral myocarditis, infective endocarditis, other causes of pericarditis such as connective tissue disease, innocent cardiac murmurs, septic arthritis, reactive arthritis, juvenile idiopathic arthritis, sickle cell disease, gout, leukemia, Wilson disease, Huntington cholera, and intracranial tumor. Proper imaging and laboratory tests can help rule out these conditions to establish a definitive diagnosis of ARF. 
The treatment plan of ARF includes antibiotic therapy, anti-inflammatory treatment and management of cardiac symptoms. The goals should include symptomatic relief, eradication of the group $A$ streptococcal infection, prophylaxis against future infection and proper education to prevent future episodes. The most convenient way to treat GAS pharyngitis is with the use of long acting penicillin $G[19,20]$. Symptomatic relief or arthritis symptoms can be provided with nonsteroidal antiinflammatory drugs such as aspirin or naproxen [21, 22]. Other options also include using low dose glucocorticoids for patients who are allergic to aspirin or naproxen. Carditis can be prevented with early echocardiography and prevention of complications.

In conclusion, acute rheumatic fever is a condition that can be treated appropriately if detected early. While it was difficult to detect the diagnosis on the patient's first visit, her second visit showed appropriate symptoms for the diagnosis. Once ARF is considered, appropriate laboratory examinations and cardiac testing should be done. Early detection and treatment can prevent the risk of complications.

\section{Conflict of interest}

The authors declare no conflict of interest.

\section{References}

1. Stollerman GH. Rheumatic fever in the 21st century. Clin Infect Dis 2001; 33: 806-14.

2. Carapetis JR, McDonald M, Wilson NJ. Acute rheumatic fever. Lancet (London, England) 2005; 366: 155-68.

3. Veasy LG, Tani LY, Hill HR. Persistence of acute rheumatic fever in the intermountain area of the United States. J Pediatr 1994; 124: 9-16.

4. Carapetis JR, Steer AC, Mulholland EK, Weber M. The global burden of group A streptococcal diseases. Lancet Infect Dis 2005; 5: 685-94.

5. Miyake CY, Gauvreau K, Tani LY, Sundel RP, Newburger JW. Characteristics of children discharged from hospitals in the United States in 2000 with the diagnosis of acute rheumatic fever. Pediatrics 2007; 120: 503-8.

6. Quinn A, Kosanke S, Fischetti VA, Factor SM, Cunningham MW. Induction of autoimmune valvular heart disease by recombinant streptococcal $\mathrm{m}$ protein. Infect Immun 2001; 69: 4072-8.

7. Anthony BF, Kaplan EL, Wannamaker LW, Briese FW, Chapman SS. Attack rates of acute nephritis after type 49 streptococcal infection of the skin and of the respiratory tract. J Clin Investig 1969; 48: 1697-704.

8. Bryant PA, Robins-Browne R, Carapetis JR, Curtis N. Some of the people, some of the time: susceptibility to acute rheumatic fever. Circulation 2009; 119: 742-53.

9. Cunningham MW, McCormack JM, Fenderson PG, Ho MK, Beachey EH, Dale JB. Human and murine antibodies cross-reactive with streptococcal $M$ protein and myosin recognize the sequence GLN-LYS-SER-LYS-GLN in M protein. J Immunol 1989; 143: 2677-83.

10. Cunningham MW, McCormack JM, Talaber LR, et al. Human monoclonal antibodies reactive with antigens of the group A Streptococcus and human heart. J Immunol 1988; 141: 2760-6.

11. Galvin JE, Hemric ME, Ward K, Cunningham MW. Cytotoxic mAb from rheumatic carditis recognizes heart valves and laminin. J Clin Investig 2000; 106: 217-24.

12. Dale JB, Beachey EH. Epitopes of streptococcal M proteins shared with cardiac myosin. J Exp Med 1985; 162: 583-91.

13. Kirvan CA, Swedo SE, Heuser JS, Cunningham MW. Mimicry and autoantibody-mediated neuronal cell signaling in Sydenham chorea. Nat Med 2003; 9: 914-20.

14. Gewitz MH, Baltimore RS, Tani LY, et al. Revision of the Jones Criteria for the diagnosis of acute rheumatic fever in the era of Doppler echocardiography: a scientific statement from the American Heart Association. Circulation 2015; 131: 1806-18.

15. Edwards WD, Peterson K, Edwards JE. Active valvulitis associated with chronic rheumatic valvular disease and active myocarditis. Circulation 1978; 57: 181-5.

16. Seckeler MD, Hoke TR. The worldwide epidemiology of acute rheumatic fever and rheumatic heart disease. Clin Epidemiol 2011; 3: 67-84.

17. Bitar FF, Hayek P, Obeid M, Gharzeddine W, Mikati M, Dbaibo GS. Rheumatic fever in children: a 15-year experience in a developing country. Pediatr Cardiol 2000; 21: 119-22.

18. Grassi A, Fesslova V, Carnelli V, et al. Clinical characteristics and cardiac outcome of acute rheumatic fever in Italy in the last 15 years. Clin Exp Rheumatol 2009; 27: 366-72.

19. Webb RH, Grant C, Harnden A. Acute rheumatic fever. BMJ 2015; 351: h3443.

20. Gerber MA, Baltimore RS, Eaton CB, et al. Prevention of rheumatic fever and diagnosis and treatment of acute Streptococcal pharyngitis: a scientific statement from the American Heart Association Rheumatic Fever, Endocarditis, and Kawasaki Disease Committee of the Council on Cardiovascular Disease in the Young, the Interdisciplinary Council on Functional Genomics and Translational Biology, and the Interdisciplinary Council on Quality of Care and Outcomes Research: endorsed by the American Academy of Pediatrics. Circulation 2009; 119: 1541-51.

21. Illingworth RS, Lorber J, Holt KS, Rendle-Short J. Acute rheumatic fever in children; a comparison of six forms of treatment in 200 cases. Lancet 1957; 273: 653-9.

22. TREATMENT of acute rheumatic fever in children a co-operative clinical trial of A.C.T.H., cortisone, and aspirin; a joint report by the Rheumatic Fever Working Party of the Medical Research Council of Great Britain and the Subcommittee of Principal Investigators of the American Council on Rheumatic Fever and Congenital Heart Disease, American Heart Association. Br Med J 1955; 1: 555-74. 